\title{
Association between angiotensin II type-1 receptor A1166C polymorphism and the presence of angiographically-defined coronary artery disease in an Iranian population
}

\begin{abstract}
AkramAssali $^{\mathrm{a}, \mathrm{b}, \mathrm{c}}$, Javad Behravan ${ }^{\mathrm{a}}$, Roghayeh Paydar ${ }^{\mathrm{b}}$, Mohsen Mouhebatie ${ }^{\mathrm{e}}$, Mitra Hassani ${ }^{\mathrm{a}}$, Jamal Kasaeyan ${ }^{\mathrm{a}}$, Farnoosh Tatari ${ }^{\mathrm{a}}$, Shima Tavallaie ${ }^{\mathrm{b}}$, Amirhossein Sahebkar ${ }^{\mathrm{a}, \mathrm{b}}$, Mohammadreza Oladi $^{\mathrm{a}}$, Mohsen Azimi-Nezhad ${ }^{\mathrm{b}}$, Majid Ghayour-Mobarhan ${ }^{\mathrm{b}, \mathrm{d}}$, Habib A. Esmaeily ${ }^{\mathrm{f}}$, Gordon Ferns ${ }^{\mathrm{g}}$

${ }^{a}$ Biotechnology Research Center, ${ }^{b}$ Cardiovascular Research Center, Avicenna Research Institute, ${ }^{d}$ Department of Biochemistry and Nutrition, Faculty of Medicine, ${ }^{e}$ Department of Cardiology, fDepartment of Statistics, Faculty of Medicine, MUMS, Mashhad, PO BOX 91775-379; 'Department of Biochemistry, Tehran Payame Noor University, Tehran, PO BOX 18335-155, Iran. ${ }^{9}$ Institute for Science and Technology in Medicine, University of Keele, Guy Hilton Research Centre, Thornburrow Drive, Stoke-on-Trent, Staffordshire ST4 7QB, UK
\end{abstract}

\begin{abstract}
Background: There are reported associations between a polymorphism of the angiotensin II type 1 receptor $\left(\mathrm{AT}_{1} \mathrm{R} / \mathrm{A} 1166 \mathrm{C}\right)$ gene and coronary artery disease $(\mathrm{CAD})$, hypertension, and myocardial infarction in some populations.

Objective: Investigate the association between A1166C polymorphism and CAD in an Iranian population.

Methods: Four hundred and thirteen patients with suspected CAD were recruited. Based on coronary angiography, the patients were classified into CAD $+(n=315)$ and CAD- $(n=98)$ groups defined as $>50 \%$ and $<50 \%$ stenosis of any major coronary artery, respectively. One hundred and thirty-five healthy subjects were also recruited as the control group. The AT $\mathrm{R}_{1}$ polymorphism was assessed using a polymerase chain reaction-restriction fragment length polymorphism (PCR-RFLP) based method.

Results: A higher frequency of the $\mathrm{AC}$ and $\mathrm{CC}$ genotypes and lower frequency of the AA genotype was observed in both $\mathrm{CAD}+$ and $\mathrm{CAD}$ - groups, compared with the control group $(\mathrm{p}<0.05)$. CAD + and $\mathrm{CAD}$ - groups also had a higher frequency of the $\mathrm{C}$ allele than controls $(\mathrm{p}<0.01)$. There was no significant difference in genotype and allele frequencies between hypertensive and non-hypertensive patients $(p>0.05)$. In addition, the AT $R$ genotype frequencies did not differ significantly among different subgroups of CAD+ patients, based on the number of affected coronary vessels $(\mathrm{p}>0.05)$.

Conclusion: The frequency $\mathrm{AT}_{1} \mathrm{R} / \mathrm{A} 1166 \mathrm{C}$ polymorphism was higher among patients with some degrees of coronary stenosis who are candidates of coronary angiography.
\end{abstract}

Keywords: Angiography, angiotensin receptor, coronary artery disease, hypertension, polymorphism

The renin-angiotensin system (RAS) comprises a cascade of processes leading to the production of angiotensin II from the angiotensinogen. Activation of RAS may play an important role in the pathophysiology of coronary artery disease (CAD). The most likely mechanism by which angiotensin converting enzyme (ACE) affects cardiovascular risk is by increasing the circulating concentrations of

Correspondence to: Dr. Majid Ghayour-Mobarhan, Department of Biochemistry and Nutrition, Faculty of Medicine, Mashhad University of Medical Science (MUMS), Mashhad, Po BOX: 91775-379, Iran. E-mail: ghayourm@mums.ac.ir 
angiotensin II and by reducing plasma bradykinin levels $[1,2]$.

Cellular effects of angiotensin II are mediated by two distinct receptor subtypes: angiotensin II type 1 $\left(\mathrm{AT}_{1}\right)$ and angiotensin II type $2\left(\mathrm{AT}_{2}\right)$ receptors [3] Angiotensin II acts predominantly via the angiotensin II type 1 receptors $\left(A_{1} R\right)$, which are present on smooth muscle cells of coronary arteries $[1,4,5]$.

The $\mathrm{AT}_{1}$ receptor gene (AF245699) has a chromosomal location of 3q21-q25 extending over a $55 \mathrm{~kb}$ segment, and comprising five exons. A single nucleotide polymorphism (SNP) in the 3-prime untranslated region (3'-UTR) of this gene (A1166C, rs5186) has been characterized and investigated in relation to hypertension, left ventricular hypertrophy, myocardial infarction (MI), carotid intima medial thickening and stroke in a limited number of patients [6-9]. However, the results have been inconsistent, and previous reports of associations between this SNP and $\mathrm{CAD}$ or hypertension have not been confirmed in some studies.

There is little information about the genetic susceptibility to CAD and hypertension in Iranian populations in spite of the high prevalence of these disorders. In this study, we aimed to investigate the A 11166C polymorphism of $\mathrm{AT}_{1} \mathrm{R}$ gene and the presence of $\mathrm{CAD}$ and hypertension in an Iranian population.

\section{Methods \\ Study population}

Five hundred forty eight subjects participated in this study. Four hundred and thirteen patients with suspected CAD who underwent coronary angiography were recruited from Ghaem Medical Center, Mashhad, Iran (245 males, 168 female; mean age $56.3 \pm 11.5$ years). The presence of CAD was defined as $>50 \%$ reduction of coronary artery diameter. Patients were classified according to the number of significant stenotic vessels as follows: angiographically-normal vessel $(n=99), 1$-vessel (SVD) $(n=107), 2$-vessel (2VD) $(n=106)$ and 3vessel (3VD) $(n=101)$ diseased groups. One hundred thirty-five subjects from a healthy population of volunteers were also recruited from two health centers as the control group (72, males and 63, females; mean age $48.8 \pm 9.9$ years). These individuals had no personal or family history of cardiovascular disease or diabetes.

The study protocol was approved by the Ethics Committee of the Mashhad University of Medical
Sciences (MUMS), and written informed consent was obtained from each participant.

\section{Anthropometric and other measurements}

Anthropometric parameters, including weight, height, body mass index (BMI), waist circumference, hip circumference, and waist/hip ratio as well as systolic and diastolic blood pressures were measured [10].

\section{Routine biochemical analysis}

A full fasted lipid profile was determined for each subject. Serum lipids and fasting blood glucose (FBS) concentrations were measured using enzymatic methods.

\section{Genetic analysis}

Whole blood was collected from the study subjects, and genomic DNA was isolated from peripheral blood leukocytes using a commercial kit (Biogen, Mashhad, Iran). The A1166C variant of $\mathrm{AT}_{1} \mathrm{R}$ gene was identified using the polymerase chain reaction (PCR) followed by restriction enzyme digestion of the amplified product, as previously described $[11,12]$. The primers used in the PCR reaction were 5'-GCACCA TGTTTTGAGT TG-3' as the forward and 5'-CGACT ACTGCTTAG CATA- $3^{\prime}$ as the reverse primer under the conditions described by Behravan et al $[12,13]$. The PCR products were digested with the DdeI restriction enzyme (MBI Fermentas, EU). Digested products were separated using electrophoresis on a $1.5 \%$ agarose gel, and visualized directly under UV light after staining with ethidium bromide. Undigested 540 bp fragment indicated the presence of the A allele and, appearance of two bands at 110 and $430 \mathrm{bp}$ represented the $\mathrm{C}$ allele [12].

\section{Statistical analysis}

All statistical analyses were performed using the SPSS for Windows (version 11.5) (SPSS, Chicago, IL USA). Data were expressed as mean \pm SD or median and interquartile range. The statistical difference in genotype and allele frequencies between the $\mathrm{CAD}+$, CAD- and control groups were assessed by the $\chi^{2}$ test. Other variables were compared using one-way ANOVA or Kruskall-Wallis test. Compliance of genotypes with the Hardy-Weinberg equilibrium in each group was assessed by $\chi^{2}$ test with one degree of freedom. A two-sided $\mathrm{p}$-value $<0.05$ was considered statistically significant. 


\section{Results}

\section{Demographic characteristics}

Among the individuals who underwent coronary angiography, 59.3\% were male. According to the results of coronary angiography, $58.9 \%$ of males and $88.2 \%$ of females had coronary artery disease. The prevalence of coronary artery disease among those undergoing angiography was significantly higher in females compared with males.

Table 1 shows the general characteristics (clinical and biochemical) of patient and control subjects. There was a significant difference between the three groups in their age and gender. Smoking habit and diabetes mellitus were more frequent in $\mathrm{CAD}+$ and CADgroups than control subjects. The family history of coronary heart disease (CHD), diabetes mellitus, stroke, and peripheral vascular disease were also higher in $\mathrm{CAD}+$ and CAD- groups compared to the controls. Waist to hip ratio was significantly higher in both $\mathrm{CAD}+$ and CAD- subjects compared to the controls whereas the difference among groups in their BMI did not reach statistical significance. In regard to the lipid profile, CAD + and CAD- groups had significantly higher levels of high-density lipoprotein cholesterol (HDL-C) and triglycerides, and lower levels of total cholesterol and low-density lipoprotein cholesterol (LDL-C) compared to the control group. This favourable status of lipid profile in CAD + and CAD- subjects may be attributed to the consumption of lipid lowering drugs. CAD + and CAD- patients had a significantly higher systolic blood pressure and FBS. Among patients, CAD+ subjects were older than CAD- subjects, and had significantly higher levels of FBS and triglycerides. Other biochemical parameters were not significantly different between $\mathrm{CAD}+$ and CAD- groups.

Table 1. Clinical and biochemical characteristics of patients and control subjects. (BMI: body mass index; TC: total cholesterol; TG: triglycerides; HDL-C: high-density lipoprotein cholesterol; LDL-C: low-density lipoprotein cholesterol; FBS: fasting blood sugar; SBP: systolic blood pressure; DBP: diastolic blood pressure; CHD: coronary heart disease; PVD: peripheral vascular disease).

\begin{tabular}{|c|c|c|c|c|}
\hline \multirow{2}{*}{ Number } & & \multirow{2}{*}{$\begin{array}{l}\text { Control } \\
135\end{array}$} & \multirow{2}{*}{$\begin{array}{l}\text { CAD- } \\
98\end{array}$} & \multirow{2}{*}{$\begin{array}{l}\text { CAD+ } \\
315\end{array}$} \\
\hline & & & & \\
\hline \multicolumn{2}{|c|}{ Gender (female/male) } & $63 / 72$ & $69 / 29^{* * *}$ & 99/216**A \\
\hline \multicolumn{2}{|c|}{ Age (years) } & $48.0 \pm 9.5$ & $52.8 \pm 12.2^{* *}$ & $57.4 \pm 11.1^{* * * \star A}$ \\
\hline \multicolumn{2}{|c|}{ Height (cm) } & $161.0 \pm 10.8$ & $153.1 \pm 29.2^{*}$ & $159.0 \pm 23.5$ \\
\hline \multicolumn{2}{|c|}{ Weight (kg) } & $71.0 \pm 13.6$ & $67.4 \pm 12.9$ & $70.6 \pm 12.8$ \\
\hline \multicolumn{2}{|c|}{ BMI $\left(\mathrm{kg} / \mathrm{m}^{2}\right)$} & $27.8 \pm 5.6$ & $27.1 \pm 5.7$ & $27.1 \pm 5.8$ \\
\hline \multicolumn{2}{|c|}{ Waist (cm) } & $87.1 \pm 21.7$ & $87.8 \pm 12.7$ & $88.6 \pm 12.3$ \\
\hline \multicolumn{2}{|l|}{ Hip (cm) } & $102.1 \pm 9.3$ & $94.9 \pm 13.0^{* * *}$ & $94.0 \pm 13.1^{* * *}$ \\
\hline \multicolumn{2}{|c|}{ Smoker (\%) } & 15.6 & $28.6^{*}$ & $38.4^{* * *}$ \\
\hline \multicolumn{2}{|c|}{ FBS (mg/dL) } & $85.6 \pm 14.5$ & $103.2 \pm 37.7^{*}$ & $119.2 \pm 55.0^{* * *}$ \\
\hline \multicolumn{2}{|c|}{ Diabetes mellitus } & 0 & $20.4^{* * *}$ & $28.9^{* * *}$ \\
\hline \multicolumn{2}{|c|}{ TC (mg/dL) } & $183.8 \pm 39.2$ & $167.5 \pm 46.7^{*}$ & $178.5 \pm 49.6$ \\
\hline \multicolumn{2}{|c|}{ LDL-C (mg/dL) } & $121.9 \pm 34.5$ & $97.7 \pm 33.1^{* * *}$ & $102.2 \pm 36.8^{* * *}$ \\
\hline \multicolumn{2}{|c|}{ HDL-C (mg/dL) } & $39.8 \pm 8.4$ & $45.9 \pm 13.3^{*}$ & $45.5 \pm 23.8^{*}$ \\
\hline \multicolumn{2}{|c|}{ TG(mg/dL) } & $101.0(71.0-142.0)$ & $109.0(83.0-156.0)^{*}$ & $135.5(95.0-192.2)^{* * * \star A}$ \\
\hline \multicolumn{2}{|c|}{ SBP (mmHg) } & $117.3 \pm 22.6$ & $141.0 \pm 28.0^{* * *}$ & $137.9 \pm 29.4^{* * *}$ \\
\hline \multicolumn{2}{|c|}{ DBP (mmHg) } & $78.8 \pm 11.5$ & $77.1 \pm 14.2$ & $78.5 \pm 14.2$ \\
\hline \multirow{4}{*}{$\begin{array}{l}\text { Family } \\
\text { history of }\end{array}$} & CHD (\%) & 0 & $17.3^{* * *}$ & $14.9^{* * * *}$ \\
\hline & Stroke (\%) & 0 & $10.2^{* * *}$ & $7.2^{* *}$ \\
\hline & Diabetes (\%) & 0 & $9.2^{* * *}$ & $14.1^{* * *}$ \\
\hline & PVD (\%) & 0 & 1 & $3.2^{*}$ \\
\hline
\end{tabular}

Values are expressed as mean \pm SD or median and interquartile range. Comparisons were made using the $\chi^{2}$ test, one-way ANOVA and Kruskal-Wallis test. ${ }^{*} \mathrm{p}<0.05,{ }^{* *} \mathrm{p}<0.001,{ }^{* * *} \mathrm{p}<0.001$, compared with the control group; ${ }^{\star} \mathrm{p}<0.05$, $\star \mathrm{A}<0.001, \cdots \wedge \mathrm{p}<0.001$, compared with the CAD- group. 


\section{Association between $A_{1} R_{1} / A 1166 C$ polymorphism and presence of CAD}

In vitro DNA amplification of the AT $\mathrm{R}_{1}$ gene using the specific primers resulted in a $540 \mathrm{bp}$ DNA product. On digestion of the amplified fragment (amplicon) with DdeI restriction endonuclease, DNA fragments of 540 (AA), 430 (CC) or 540 and 430 (AC) bp length were observed. Thus, each sample revealed one of three different electrophoretic patterns.

Table 2 shows genotype and allele frequencies of $\mathrm{AT}_{1} \mathrm{R} / \mathrm{A} 1166 \mathrm{C}$ polymorphism in $\mathrm{CAD}+, \mathrm{CAD}$ - and control subjects. Overally, among a total of 413 patients, the frequencies of AA, $\mathrm{AC}$, and $\mathrm{CC}$ genotypes were $66.0 \%$ (208 cases), $25.1 \%$ (79 cases), and $8.9 \%$ ( 28 cases) in the CAD + and $69.4 \%$ (68 cases), $24.5 \%$ ( 24 cases), and $6.1 \%$ (6 cases) in the CADgroup, respectively. Likewise, among 135 control subjects, the frequencies of $\mathrm{AA}, \mathrm{AC}$, and $\mathrm{CC}$ genotypes were $86.7 \%$ (117 cases), $11.8 \%$ (16 cases), and $1.5 \%$ ( 2 cases), respectively. The genotype distribution in the $\mathrm{CAD}$ - and control groups was consistent with the Hardy-Weinburg equilibrium $(p>0.05)$. However, a significant deviation from the equilibrium was observed in the $\mathrm{CAD}+$ group $(\mathrm{p}<0.001)$. The frequency of $\mathrm{A}$ and $\mathrm{C}$ alleles 0.786 and 0.214 in the $\mathrm{CAD}+$ patients, 0.816 and 0.184 in the CAD- patients, and 0.926 and 0.074 in the control group, respectively. A higher frequency of the $\mathrm{AC}$ and $\mathrm{CC}$ genotypes was observed in both $\mathrm{CAD}+$ and $\mathrm{CAD}-$ patients when compared with the control group ( $p \leq 0.05$ ). On the other hand, the frequency of AA homozoygotes was significantly higher in the control subjects compared to the $\mathrm{CAD}+$ and CAD-subjects $(\mathrm{p}<0.01)$. In regard to the allele frequencies, a significantly higher frequency of the $\mathrm{C}$ allele was observed in the $\mathrm{CAD}+$ and $\mathrm{CAD}$ - groups compared to the control group $(p<0.01)$. Notably, there was no significant difference between $\mathrm{CAD}+$ and CADgroups, neither in the genotype distribution nor in their allele frequencies $(\mathrm{p}>0.05)$.

In regard to the number of stenosed coronary vessels, no significant difference in the genotype distribution or allele frequencies was detected between subgroups with one (SVD), two (2VD), and three (3VD) affected vessels except for a significant difference in allele frequencies between SVD and 3 VD groups $(p<0.05$, Table 3 ).

Table 2. Genotype and allele frequencies of $\mathrm{AT}_{1} \mathrm{R} / \mathrm{A} 1166 \mathrm{C}$ polymorphism in CAD + , CAD- and control subjects.

\begin{tabular}{llll}
\hline & Control & CAD- & CAD+ \\
\hline Genotype frequency & $117(86.7)$ & $68(69.4)^{* * *}$ & $208(66.0)^{* * * *}$ \\
AA & $16(11.9)$ & $24(24.5)^{* *}$ & $79(25.1)^{* *}$ \\
AC & $2(1.5)$ & $6(6.1)^{*}$ & $28(8.9)^{* * *}$ \\
CC & & & \\
Allele frequency & $250(92.6)$ & $160(81.6)^{* * *}$ & $495(78.6)^{* * *}$ \\
A & $20(7.4)$ & $36(18.4)^{* *}$ & $135(21.4)^{* * *}$ \\
C &
\end{tabular}

Values are expressed as number (\%). Comparisons were made by the $\chi^{2}$ test. ${ }^{*} \mathrm{p}<0.05,{ }^{* *} \mathrm{p}<0.001,{ }^{* * *} \mathrm{p}<0.001$, compared with the control group; $₫ p=0.05$, compared with the control group.

Table 3. Genotype and allele frequencies of $\mathrm{AT}_{1} \mathrm{R} / \mathrm{A} 1166 \mathrm{C}$ polymorphism in the CAD-patients and subgroups of CAD + patients based on the number of affected coronary vessels.

\begin{tabular}{lllll}
\hline & CAD- & SVD & 2VD & 3VD \\
\hline Genotype frequency & $68(69.4)$ & $67(62.6)$ & $68(64.2)$ & $73(72.3)$ \\
AA & $24(24.5)$ & $27(25.2)$ & $28(26.4)$ & $23(22.8)$ \\
AC & $6(6.1)$ & $13(12.2)$ & $10(9.4)$ & $5(4.9)$ \\
CC & & $161(75.2)$ & $164(77.4)$ & $169(83.7)^{*}$ \\
Allele frequency & $160(81.6)$ & $53(24.8)$ & $48(22.6)$ & $33(16.3)^{*}$ \\
A & $36(18.4)$ & & \\
C
\end{tabular}

Values are expressed as number (\%). Comparisons were made using the $\chi^{2}$ test. ${ }^{*} p<0.001$, compared with the SVD group. SVD: single vessel disease; 2VD: two-vessel disease; 3VD: three-vessel disease. 


\section{Association between $A T_{1} R / A 1166 C$ polymorphism and hypertension}

In our study, the prevalence of hypertension was significantly higher in females $(50.0 \%)$ compared to males $(31.0 \%)(\mathrm{p}<0.05)$. The genotype and allele frequencies did not differ significantly between hypertensive and non-hypertensive subjects

(Table 4).

\section{Discussion}

CAD is the most common underlying cause of the heart disease $[14,15]$. The involvement of an inherited genetic component is supported by strong familial tendency to CAD [16]. Therefore, identification of susceptibility genes for this prevalent and multifactorial disease is of high importance to public health. There have been few studies concerning the identification of genetic determinants of CAD in Iranian population.

In a previous study, Alvarez et al. [17] did not find a significant difference in the frequency of $\mathrm{AT}_{1} \mathrm{R}$ genotypes between Caucasian patients with early $\mathrm{CAD}$ and healthy control subjects. However, they reported a synergistic contribution of $A C E$ and $A_{1} R$ polymorphisms to the risk of coronary artery disease. The lack of significant difference in the genotype distribution and allele frequencies of the A1166C SNP was also confirmed in other studies performed in patients with $\mathrm{CHD}$ and coronary artery bypass grafting [18, 19]. However, Gardemann et al. [1] failed to observe any significant difference in A1166C genotypes between patients with and without CAD or MI. This latter finding is consistent with that of some other studies [4, 20-23]. In addition, in another investigation, the $\mathrm{AT}_{1} \mathrm{R}$ genotypes were not found to be significantly associated with cardiovascular outcomes in neither African American subjects nor whites [24].

Despite the findings of aforementioned reports, the AA genotype of $\mathrm{AT}_{1} \mathrm{R}$ gene was associated with decreased risk of premature CHD in Turkish subjects [25]. On the other hand, in Italian subjects, Fatini et al. [27] reported a significant association between $\mathrm{AT}_{1} \mathrm{R}$ CC genotype and the presence of CHD [26]. This finding was also confirmed in a later study on male subjects with CHD [27]. Moreover, the $\mathrm{C}$ allele of the $\mathrm{AT}_{1} \mathrm{R}$ gene was previously reported to be associated with the severity of CHD in Japanese patients [23] and development of the stenosis of coronary artery in Chinese patients [18]. The higher prevalence of the $\mathrm{CC}$ genotype and $\mathrm{C}$ allele of the $\mathrm{AT}_{1} \mathrm{R}$ gene have also been reported in cases with $\mathrm{MI}$, which jointly support a plausible role for the $\mathrm{C}$ allele in the pathogenesis of CHD [28-30]. It was hypothesized that the adverse effects of the $1166 \mathrm{C}$ allele is due to the increased responsiveness to angiotensin II [31], and complications such as vasoconstriction [32] as well as cardiac and vascular hypertrophy [33]. In the present study, we did not observe any significant difference in genotype or allele frequencies between $\mathrm{CAD}+$ and CAD- groups. However, it is worth noting that the CAD- subjects with $<50 \%$ stenosis might have degrees of CAD that may progress to overt CAD over time. Moreover, $\mathrm{CAD}$ - subjects were significantly younger than $\mathrm{CAD}+$ patients (about five years) and had relatively high frequency of diabetes mellitus and family history of CHD. Therefore, the probability that some of these subjects may become $\mathrm{CAD}+$ within five years should be considered.

Table 4. Genotype and allele frequencies of $\mathrm{AT}_{1} \mathrm{R} / \mathrm{A} 1166 \mathrm{C}$ polymorphism in hypertensive and nonhypertensive subgroups patients.

\begin{tabular}{lll}
\hline & Hypertensive & Non-hypertensive \\
\hline Genotype frequency & & \\
AA & $117(66.8)$ & $159(66.8)$ \\
AC & $43(24.6)$ & $60(25.2)$ \\
CC & $15(8.6)$ & $19(8.0)$ \\
Allele frequency & & \\
A & $277(79.1)$ & $378(79.4)$ \\
C & $73(20.9)$ & $100(20.6)$
\end{tabular}

Values are expressed as number (\%). No significant difference in genotype or allele frequencies was observed $(\mathrm{p}>0.05)$. 
In the present study, we did not observe any significant difference between hypertensive and non-hypertensive patients in genotypes nor in their allele frequencies. Previously, several studies have reported an association between A1166C polymorphism and hypertension, and higher frequencies of this SNP have been observed in hypertensive patients $[6,34,35]$. However, these results have not been well consistent. In some studies, subjects with CC genotype have been reported with lower blood pressure and cardiovascular risk [36, 37], while others have shown higher frequency of $\mathrm{C}$ allele or CC genotype among hypertensive subjects $[4,35$, 38]. Concerning the Iranian population, Behravan et al. [13] reported no significant difference in genotype distribution or allele frequencies between hypertensive and normo-tensive subjects when the combined males and females were analyzed. Their result is consistent with our findings [13]. Furthermore, some other studies also failed to report any significant difference in genotype distribution between hypertensive and normo-tensive subjects or any significant association between A1166C polymorphism and hypertension [11, 39-41].

\section{Conclusion}

We observed significant differences in the frequency of $\mathrm{AA}, \mathrm{AC}$, and $\mathrm{CC}$ genotypes between patients with suspected CAD and controls. The frequency of polymorphic genotypes (AC and $\mathrm{CC}$ ) was higher between $\mathrm{CAD}+$ and $\mathrm{CAD}$ - patients compared with the control subjects. The carriers of the $\mathrm{C}$ allele were also significantly higher in $\mathrm{CAD}+$ and CAD- groups compared with the control group. The main reason for the discrepant findings on the association between $\mathrm{A} 1166 \mathrm{C}$ polymorphism and CAD or hypertension, may be the complex nature of geneenvironment interactions in the pathophysiology of these diseases. Therefore, conflicting results in different populations could be attributed to the differences in lifestyle or diet that affect the genetic predisposition to $\mathrm{CAD}$. Together with environmental factors, the involvement of multiple genes in the pathophysiology of CAD is another factor responsible for the uncertainties in correct risk assessment of the disease. Indeed, it is difficult to identify a single polymorphism as a risk factor for a polygenic and multifactorial disease. To obtain more reliable results, it may be better to study the association between different polymorphisms and CAD jointly (e.g. by linkage studies).

\section{Acknowledgements}

The authors sincerely thank all of the subjects who participated in the study. Financial support of the present work by the Research Council of the Mashhad University of Medical Sciences (MUMS) is also greatly acknowledged. The authors have no conflict of interest to declare.

\section{References}

1. Gardemann A, Nguyen QD, Humme J, Stricker J, Katz $\mathrm{N}$, Tillmanns H, et al. Angiotensin II type 1 receptor A1166C gene polymorphism. Absence of an association with the risk of coronary artery disease and myocardial infarction and of a synergistic effect with angiotensin-converting enzyme gene polymorphism on the risk of these diseases. Eur Heart J. 1998; 19:1657-65.

2. Companioni Napoles O, Sautie Castellanos M, Leal L, Casalvilla R, Camacho H, Ferrer A, et al. ACE I/D polymorphism study in a cuban hypertensive population. Clin Chim Acta. 2007; 378:112-6.

3. Ulgen MS, Ozturk O, Yazici M, Kayrak M, Alan S, Koc F, et al. Association between A/C1166 gene polymorphism of the angiotensin II type 1 receptor and biventricular functions in patients with acute myocardial infarction. Circ J. 2006; 70:1275-9.

4. Tiret L, Bonnardeaux A, Poirier O, Ricard S, MarquesVidal P, Evans A, et al. Synergistic effects of angiotensin-converting enzyme and angiotensin-II type 1 receptor gene polymorphisms on risk of myocardial infarction. Lancet. 1994; 344:910-3.

5. Ozturk O, Ozturk U, Bilici A. The effect of angiotensin II type-1 receptor gene polymorphisms on doppler blood flow parameters of carotid and brachial arteries in patients with myocardial infarction. Echocardiography. 2006; 23:536-41.

6. Stankovic A, Zivkovic M, Glisic S, Alavantic D. Angiotensin II type 1 receptor gene polymorphism and essential hypertension in Serbian population. Clin Chim Acta. 2003; 327:181-5.

7. Chistiakov DA, Kobalova ZD, Tereshchenko SN, Moiseev SV, Nosikov VV. Polymorphism of vascular angiotensin II receptor gene and cardiovascular disorders. Ter Arkh. 2000; 72:27-30.

8. Chapman CML, Palmer LJ, McQuillan BM, Hung J, Burley J, Hunt C, et al. Polymorphisms in the angiotensinogen gene are associated with carotid intimal-medial thickening in females from a communitybased population. Atherosclerosis. 2001; 159:209-17.

9. Takami S, Imai Y, Katsuya T, Ohkubo T, Tsuji I, Nagai 
$\mathrm{K}$, et al. Gene polymorphism of the renin-angiotensin system associates with risk for lacunar infarction: the Ohasama study. Am J Hypertens. 2000; 13:121-7.

10. Ghayour-Mobarhan M, Sahebkar A, Parizadeh SMR, Moohebati M, Tavallaie S, Kazemi-Bajestani SMR, Esmaeili HA, Ferns G. Antibody titres to heat shock protein 27 are elevated in patients with acute coronary syndrome. Int J Exp Pathol. 2008; 89:209-15.

11. Lahiri DK, Nurnberger JI Jr. A rapid non-enzymatic method for the preparation of HMW DNA from blood for RFLP studies. Nucleic Acids Res. 1991; 19:5444.

12. Reich H, Duncan JA, Weinstein J, Cattran DC, Scholey JW, Miller JA. Interactions between gender and the angiotensin type 1 receptor gene polymorphism. Kidney Int. 2003; 63:1443-9.

13. Behravan J, Naghibi M, Mazloomi MA, Hassany M. Polymorphism of Angiotensin II type 1 receptor gene in essential hypertension in Iranian population. Daru. 2006; 19:482-5

14. World Health Organization. World health statistics report 2008. Geneva: WHO, 2008. http://www.who.int/ whosis/whostat/2008/en/index.html (accessed 19 September 2009).

15. American Heart Association, Heart Disease and Stroke Statistics - 2003 update. American Heart Association, Dallas, USA, 2002.

16. Marmot MG, Syme SL, Kagan A, Kato H, Cohen JB, Belsky J. Epidemiologic studies of coronary heart disease and stroke in Japanese men living in Japan, Hawaii and California: prevalence of coronary and hypertensive heart disease and associated risk factors. Am J Epidemiol. 1975; 102:514.

17. Alvarez R, Reguero JR, Batalla A, Iglesias-Cubero G, Cortina A, Alvarez V, et al. Angiotensin-converting enzyme and angiotensin II receptor 1 polymorphisms: association with early coronary disease. Cardiovasc Res. 1998; 40:375-9.

18. Qiu C, Han Z, Lu W, Zhang C. Association of polymorphisms in angiotensin-converting enzyme and type 1 angiotensin II receptor genes with coronary heart disease and the severity of coronary artery stenosis. J Huazhong Univ Sci Technol Med Sci. 2008; 27:660-3.

19. Ozisik K, Misirlioglu M, Ulus TA, Tuncer S, Emir M, Katircioglu F. Renin-angiotensin system polymorphisms and coronary artery surgery patients. Asian Cardiovasc Thorac Ann. 2005; 13:153-6.

20. Araujo MA, Menezes BS, Lourenco C, Cordeiro ER, Gatti RR, Goulart LR. The A1166C polymorphism of the angiotensin II type-1 receptor in acute myocardial infarction. Arq Bras Cardiol. 2004; 83:409-13.

21. Niemiec P, Zak I, Wita K. The risk of coronary artery disease associated with cigarette smoking and hypercholesterolemia is additionally increased by the presence of the AT 1R gene 1166C allele. Biochem Genet. 2008; 46:799-809.

22. Andrikopoulos GK, Richter DJ, Needham EW, Tzeis SE, Zairis MN, Gialafos EJ, et al. The paradoxical association of common polymorphisms of the reninangiotensin system genes with risk of myocardial infarction. Eur J Cardiovasc Prev Rehabil. 2004; 11: 477-83.

23. Nakauchi Y, Suehiro T, Yamamoto M, Yasuoka N, Arii K, Kumon Y, et al. Significance of angiotensin Iconverting enzyme and angiotensin II type 1 receptor gene polymorphisms as risk factors for coronary heart disease. Atherosclerosis. 1996; 125:161-9.

24. Hindorff LA, Heckbert SR, Tracy R, Tang Z, Psaty BM, Edwards KL, et al. Angiotensin II type 1 receptor polymorphisms in the cardiovascular health study: Relation to blood pressure, ethnicity, and cardiovascular events. Am J Hypertens. 2002; 15: 1050-6.

25. Sekuri C, Cam FS, Ercan E, Tengiz I, Sagcan A, Eser E, et al. Renin-angiotensin system gene polymorphisms and premature coronary heart disease. J Renin Angiotensin Aldosterone Syst. 2005; 6:38-42.

26. Fatini C, Abbate R, Pepe G, Battaglini B, Gensini F, Ruggiano G, et al. Searching for a better assessment of the individual coronary risk profile. The role of angiotensin-converting enzyme, angiotensin II type 1 receptor and angiotensinogen gene polymorphisms. Eur Heart J. 2000; 21:633-8.

27. Buraczyńska M, Pijanowski Z, Spasiewicz D, Nowicka T, Sodolski T, Widomska-Czekajska T, et al. Renin-angiotensin system gene polymorphisms: Assessment of the risk of coronary heart disease. Kardiol Pol. 2003; 58:1-8.

28. Berge KE, Bakken A, Bohn M, Erikssen J, Berg K. A DNA polymorphism at the angiotensin II type 1 receptor (AT1R) locus and myocardial infarction. Clin Genet. 1997; 52:71-6.

29. Wierzbicki AS, Lambert-Hammill L, Lumb PJ, Crook MA. Renin-angiotensin system polymorphisms and coronary events in familial hypercholesterolemia. Hypertension. 2000; 36:633-8.

30. Cheng S, Pallaud C, Grow MA, Scharf SJ, Erlich HA, Klitz W, et al. A multilocus genotyping assay for cardiovascular disease. Clin Chem Lab Med. 1998; 36 : 561-6. 
31. Van Geel PP, Pinto YM, Buikema H, Van Gilst WH. Is the $\mathrm{A} 1166 \mathrm{C}$ polymorphism of the angiotensin II type 1 receptor involved in cardiovascular disease? Eur Heart J. 1998; 19:G13-17.

32. Amant C, Hamon M, Bauters C, Richard F, Helbecque N, McFadden EP, et al. The angiotensin II type 1 receptor gene polymorphism is associated with coronary artery vasoconstriction. J Am Coll Cardiol. 1997; 29:486-90.

33. Osterop APRM, Kofflard MJM, Sandkuijl LA, Ten Cate FJ, Krams R, Schalekamp MADH, et al. AT1 receptor A/C1166 polymorphism contributes to cardiac hypertrophy in subjects with hypertrophic cardiomyopathy. Hypertension. 1998; 32:825-30.

34. Kobashi G, Hata A, Ohta K, Yamada H, Kato EH, Minakami H, et al. A1166C variant of angiotensin II type 1 receptor gene is associated with severe hypertension in pregnancy independently of T235 variant of angiotensinogen gene. J Hum Genet. 2004; 49:182-6.

35. Wang WYS, Zee RYL, Morris BJ. Association of angiotensin II type 1 receptor gene polymorphism with essential hypertension. Clin Genet. 1997; 51:31-4.

36. Abdollahi MR, Gaunt TR, Syddall HE, Cooper C, Phillips DIW, Ye S, et al. Angiotensin II type I receptor gene polymorphism: Anthropometric and metabolic syndrome traits. J Med Genet. 2005; 42: 396-401.

37. Castellano M, Muiesan ML, Beschi M, Rizzoni D, Cinelli A, Salvetti M, et al. Angiotensin II type 1 receptor A/C1166 polymorphism: Relationships with blood pressure and cardiovascular structure. Hypertension. 1996; 28:1076-80.

38. Jiang Z, Zhao W, Yu F, Xu G. Association of angiotensin II type 1 receptor gene polymorphism with essential hypertension. Chin Med J. 2001; 114 : 1249-51.

39. Schmidt S, Beige S, Walla-Friedel M, Michel MC, Sharma AM, Ritz E. A polymorphism in the gene for the angiotensin II type 1 receptor is not associated with hypertension. J Hypertens. 1997; 15:1385-8.

40. Ono K, Mannami T, Baba S, Yasui N, Ogihara T, Iwai $\mathrm{N}$. Lack of association between angiotensin II type 1 receptor gene polymorphism and hypertension in japanese. Hypertens Res. 2003; 26:131-4.

41. Redon J, Luque-Otero M, Martell N, Chaves FJ. Renin-angiotensin system gene polymorphisms: relationship with blood pressure and microalbuminuria in telmisartan-treated hypertensive patients. Pharmacogenomics J. 2005; 5:14-20. 